\title{
PYOGENIC GRANULOMA IN PREGNANCY: A STUDY AT LIAQUAT UNIVERSITY HOSPITAL.
}

1. BDS

Dental Surgeon

Oral \& Maxillofacial Surgery LUMHS.

2. MBBS, MS (General Surgery)

Associate Professor General

Surgery

LUMHS, Jamshoro.

3. BDS, MSc

Senior Registrar Periodontology

Dr Ishrat UI Ebad Khan Institute of

Oral Health Sciences DUHS.

4. BDS, MSc (OMFS)

Lecturer

Oral \& Maxillofacial Surgery

LUMHS.

Correspondence Address:

Dr. Salman Shams

B 1/2 Sajjadabad Society Near Citizen

Colony Hyderabad

salman_omfs@hotmail.com

Article received on:

28/03/2019

Accepted for publication:

25/08/2019

\begin{abstract}
Bushra Arain ${ }^{1}$, Agha Taj Mohammed ${ }^{2}$, Batool Bibi ${ }^{3}$, Salman Shams ${ }^{4}$
\end{abstract}
\begin{abstract}
Objectives: To evaluate pattern and presentation of pyogenic granuloma in pregnant patients. Study Design: Descriptive study with non-probability purposive technique. Setting: Department of Oral \& Maxillofacial Surgery Liaquat University hospital Hyderabad. Period: From February 2013 to January 2017. Material \& Methods: A total number of fifty pregnant patients were included in the study and preliminary diagnosis of gingival pyogenic granuloma was made clinically. The clinical diagnosis was confirmed by excisional biopsy under local anesthesia (surgical procedure was done following consultation with primary care physician in second trimester or after parturition), and sent for histopathological examination. Removal of dental plaque performed before surgical therapy. Results: Most of the females involve were in age group of 21-30 (68\%). Maxillary anterior region was most frequently involved followed by mandibular anterior region. The smallest size of lesion was $1.5 \mathrm{~mm}$ and largest was $3 \mathrm{~cm}$. Conclusion: Pyogenic granuloma in pregnancy occur due to hormonal imbalance, however bacterial dental plaque, calculus and poor oral hygiene are also key factors in development.
\end{abstract}

Key words: Granuloma, Lesion, Pyogenic, Pregnancy, Plaque.

Article Citation: Arain B, Mohammed AT, Bibi B, Shams S. Pyogenic granuloma in pregnancy: A study at Liaquat University Hospital. Professional Med $\mathrm{J}$ 2020; 27(3):673-676. DOI: 10.29309/TPMJ/2020.27.3.3465

\section{INTRODUCTION}

Pyogenic granuloma or pregnancy epulis means localized inflammatory tumor like lump or cellular proliferation on gingiva, it may also describes chronic inflammatory hyperplasia. ${ }^{1}$ The first case was reported by Hullihen in 1844 and termed as pyogenic granuloma but currently histological term is lobular capillary hemangioma. ${ }^{2}$ It is hyperactive benign neoplasm occurring usually in 2nd trimester of pregnancy. ${ }^{3}$

The term is considered as misnomer as it does not present true granuloma. because lesion is not associated with pus or infection. ${ }^{4}$

On clinical grounds it is smooth lobulated exophytic lesion with erythromatous papules that have immense predisposition to bleed on palpation and typically it is painless and soft in character. Early lesion is more hemorrhagic das it appears axtremely vascular but in maturation phase it appears collagenous and less vascular. ${ }^{5}$
Interdental papilla of anterior maxillary teeth is the site where this lesion is mostly located. The gingiva is most commonly involved but tongue, lip, oral mucosa and palate might be involved. ${ }^{6}$ This lesions also occur in pregnancy, so it is also called pregnancy tumor. ${ }^{7}$

Etiology of pregnancy tumor is due to hormonal imbalance especially elevated progesterone level, repeated chronic inflammation, local irritant, plaque, bacteria and trauma is always associated with epulis. ${ }^{8}$

High level of progesterone and estrogen hormones stimulated basal and spinous stratum of epithelium and connective tissues, Progesterone dilate blood vessels and increased capillary proliferation and estrogen regulate proliferation of gingival tissues. ${ }^{3}$

Radiographicaly pyogenic granuloma finding are usually absent, localized bone resoption usually 
present in long standing tumor. Treatment during period of pregnancy is very important, care of oral hygiene, removal of calculus and soft brushing is important to avoid occurrence of epulis. Surgical treatment should be completed if justified in only $2^{\text {nd }}$ trimester. $^{9}$

\section{METHODOLOGY}

This descriptive study with non probability purposive technique was conduct at oral and maxillofacial surgery department of Liaquat university hospital Hyderabad at outdoor department, in four year period.

A total number of fifty pregnant patients were included in the study and preliminary diagnosis of gingival pyogenic granuloma was made clinically (color ranging from red to purple, smooth or lobulated, size of lesion, location, tenderness).

Question were asked regarding occlusal interference of lesion, bleeding from lesion after little or no trauma, trimester of pregnancy during epulis develop and maintenance of oral hygiene. The clinical diagnosis was confirmed by excisional biopsy under local anesthesia (surgical procedure was done following consultation with primary care physician in second trimester or after parturition), and sent for histopathological examination. Removal of dental plaque performed before surgical therapy.

Data was entered and analyzed with statistical package for social sciences (SPSS) version 16.0. An appropriate format was designed for data entry, storage of information of clinical findings. Graphical software program was developed with help of qualified software programmer.

\section{RESULTS}

Fifty pregnant patients were observed in this study. In terms of age group maximum number of patients $34(68 \%)$ were in $21-30$ years of age group, followed by 16 (32\%) patients in the 31-40 years of age. Figure- 1 shows percentage of age wise distribution of patients.

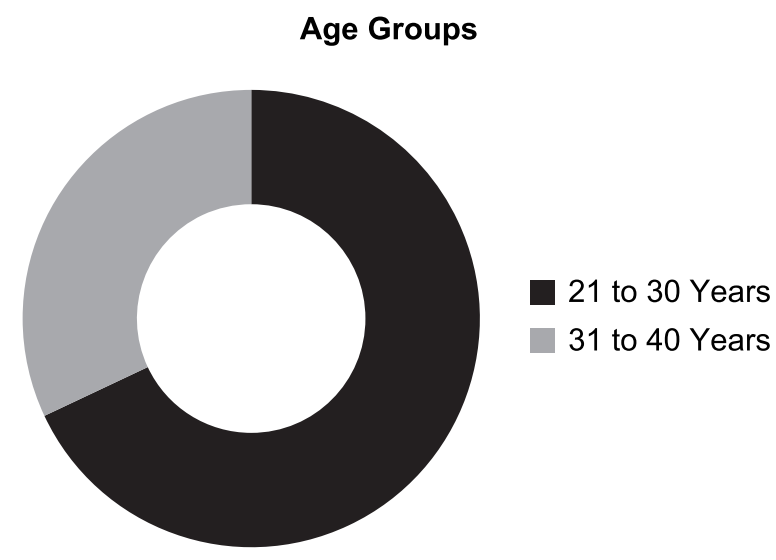

Figure-1. Distribution of age groups

In the present study maxilla is more affected than mandible. The most common site of occurrence is anterior maxillary area followed by anterior mandibular, maxillary posterior, mandibular posteriors. See (Table-I) for complete details.

\begin{tabular}{|l|c|c|}
\hline \multicolumn{1}{|c|}{ Site of Lesion } & No. of Patients & $\%$ \\
\hline Maxillary Anterior Area & 24 & $48 \%$ \\
\hline Maxillary Posterior Area & 05 & $10 \%$ \\
\hline Mandibular Anterior Area & 18 & $36 \%$ \\
\hline Mandibular Posterior Area & 03 & $06 \%$ \\
\hline Total & 50 & $100 \%$ \\
\hline
\end{tabular}

Table-I. Shows anatomic location of Lesion

There was a greater variation in size of granuloma, the smallest size of lesion was $1.5 \mathrm{~mm}$ and largest was $3 \mathrm{~cm}$. It was found that lesion usually appears during second or third trimester of pregnancy with a great tendency to bleed. We have divided the patients in two categories.

Catergory 1: Patients with size less than $1 \mathrm{~cm}$ Catergory 1: Patients with size greater than $1 \mathrm{~cm}$ See Table-II for details.

\begin{tabular}{|c|c|c|}
\hline \multicolumn{1}{|c|}{ Size of Lesion } & No. of Patients & $\%$ \\
\hline Less than 1cm & 31 & $62 \%$ \\
\hline Greater than 1cm & 19 & $38 \%$ \\
\hline Total & 50 & \\
\hline \multicolumn{2}{|c|}{ Table-Il. Shows size of Lesion } \\
\hline
\end{tabular}

A direct relation between pyogenic granuloma and severity of plaque and calculus was seen 
in our study; almost all patients had prolonged exposure of dental plaque, poor oral hygiene, as well as malocclusion and anatomical abnormalities which favor plaque retention.

\section{DISSCUSSION}

Pyogenic granuloma is a common solitary, lobulated, non-neoplastic inflammatory and highly vascular proliferation, mostly involve gingiva and rarely involve other sites of oral cavity. ${ }^{10}$ It is strongly associated with hormones such as increased concentrations of circulating estrogen or progesterone, also in presence of local irritants and trauma. The mechanism by which these steroids increase gingival inflammation is not known. Steroid hormones may have dual effects on the pathogenesis of pregnancy, hormones increased angiogenic factors in inflamed tissue, and also decrease apoptosis of granuloma. ${ }^{11,12}$

The present study specified a correlation between pregnancy related hormones and calculus or plaque formation, results shows that almost all pregnant patients suffering from pyogenic granuloma also must have bacterial plaque. Recurrent insignificant gingival inflammation secondary to plaque, calculus and trauma are enough for development of lesion, these factors necessary for subclinical hormonal changes and to lead gingivitis. According to Kapoor and Malhotra, they reported that pregnancy accentuates the gingival response to plaque. ${ }^{13}$ The correlation between gingivitis and quantity of plaque was greater after parturition than during pregnancy.

Ramesh A \& Prakash AP reported same etiology, according to them pregnancy itself cannot cause gingivitis, it is bacterial hormonal interaction, may change composition of plaque their by lead to gingival inflammation. ${ }^{14}$

Based on clinical examination our findings indicated maxillary anterior area was mostly affected followed by mandibular anterior, maxillary posterior, mandibular posterior region. Facial aspect of gingiva is more common as compare to palatal or lingual aspect of gingiva. Jafarzadeh $\mathrm{H}$ et al (2006) reported that pyogenic granuloma are much more common on maxillary gingiva than mandibular gingival. ${ }^{16} \mathrm{He}$ also reported that anterior region is more affected than posterior region. Ramesh ${ }^{14}$ similarly described maxillary gingiva (especially in the anterior region) is involved more frequently than mandibular gingival.

Pushpendra (2012) ${ }^{4}$ reported that Pyogenic granuloma grows in size from a few millimeters to several centimetres in size but rarely exceed more than $2.5 \mathrm{~cm}$ but many of the pyogenic granulomas grow rapidly and attain large sizes. In our study we found almost same results, according our research the smallest lesion was from few $\mathrm{mm}$ to largest as in $\mathrm{cm}$.

In this study it was established that lesion usually appears during second/third trimester of pregnancy with susceptibility to bleed and possible disturbance with mastication, Baldava RS et al (2011) suggested that pyogenic granuloma appears in second or third trimester of pregnancy with tendency to bleed and possible interference with mastication. ${ }^{15}$

\section{CONCLUSION}

It was concluded that pyogenic granuloma in pregnancy is hormonal induced but aggravates due to dental plaque accumulation, calculus, poor oral hygiene. It usually occurs in second and third trimester of pregnancy with peak age involved is 21 to $30 y e a r s$. It is also concluded that maxillary anterior region is most commonly affected with these types of lesions.

\section{Copyright(C) 25 Aug, 2019.}

\section{REFERENCES}

1. Newadkar UR, Khairnar S, Dodamani A. Pyogenic granuloma: A clinicopathological analysis of fifty cases. J Oral Res Rev 2018; 10:7-10.

2. Saravana $\mathrm{GH}$. Oral pyogenic granuloma: A review of 137 cases. Br J Oral Maxillofac Surg 2009; 47:318-9.

3. Fatma Ucan Y, Ozge G. Pyogenic granuloma in pregnancy: A case report. Biomed J Sci \& Tech Res. 2018; 5(1):1-3. 
4. Verma PK, Srivastava R, Baranwal HC, Chaturvedi TP, Gautam A, Singh A. Pyogenic granuloma-hyperplastic lesion of the gingiva: Case reports. Open Dent J 2012; 6:153-56.

5. Nisha $S$, Shivamallu $A B$, Hedge U. Oral pregnancy tumor. J Dent Allied Sci 2018; 7:47-50.

6. Parajuli R, Maharjan S. Unusual presentation of oral pyogenic granulomas: A review of two cases. Clin Case Rep. 2018; 6(4):690-693.

7. Kamal R, Dahya P, Puri A. Oral Pyogenic granuloma: Various concept of Etiopathogenesis; $J$ Oral Maxillofac Pathol. 2012; 16; 79-82.

8. Rosa C, Lay AC, Torre ACL. Oral pyogenic granuloma diagnosis and treatment; A series of cases. Rev Odont Mex 2017; 21 (4):244-252.

9. Narendra S, Bose C, Rout N. Oral pyogenic granuloma: One reactive hyperplastic lesion of the gingiva Int $\mathrm{J}$ Res Med Sci. 2015; 3(12):3863-3868.

10. Pereira T, Tamgade A et al. Pregnancy tumor A case report. Scientific Journal 2007; 1: DOI: 10.13140/2.1.3823.6807.
11. Ovadia R, Zirdok R, Diaz MR. Relationship between pregnancy and periodontal disease; Med Biol 2007; 14:10-14.

12. Martins-Filho PRS, Piva MR et al. Aggressive pregnancy tumor (pyogenic granuloma) with extensive alveolar bone loss mimicking a malignant tumor: Case report and review of literature. Int. J. Morphol 2011:29(1):164167.

13. Kapoor A, Malhotra R, Grover V. Pregnancy associated gingival enlargement. J Oral Health Comm Dent 2010; 4(2):48-51.

14. Ramesh A, Prakash AP. Recurrent pyogenic graulomaA case report. NUJHS 2013;5(1):83-85.

15. Baldawa RS, Saluja HM, Kasat JV, Baheti SG. An unusually large oral pregnancy tumor. Pravara Med Rev 2011; 3(4):23-26.

16. Jafarzadeh $\mathrm{H}$, Sanatkhani $\mathrm{M}$. Oral pyogenic granuloma: A review. J Oral Sci 2006; 48(4):167-75.

\begin{tabular}{|c|c|c|c|}
\hline \multicolumn{4}{|c|}{ AUTHORSHIP AND CONTRIBUTION DECLARATION } \\
\hline Sr. \# & Author(s) Full Name & Contribution to the paper & Author(s) Signature \\
\hline 1 & $\begin{array}{l}\text { Bushra Arain } \\
\text { Aaha Tai Mohammed }\end{array}$ & $\begin{array}{l}\text { Principal author, Data } \\
\text { collection. } \\
\text { Discussion. References. }\end{array}$ & \\
\hline 3 & Batool Bibi & Manuscript designing. & \\
\hline 4 & Salman Shams & $\begin{array}{l}\text { Data collection, Results \& } \\
\text { Proof reead. }\end{array}$ & \\
\hline
\end{tabular}

